\title{
A Proposed Pedagogical Mobile Application for Learning Sign Language
}

\author{
http://dx.doi.org/10.3991/ijim.v7i1.2387 \\ M. Samir Abou El-Seoud ${ }^{1}$, Ann Nosseir ${ }^{1}$, Islam Taj-Eddin ${ }^{1}$, Hosam El-Sofany ${ }^{2}$, Nadine Abu Rumman ${ }^{3}$ \\ ${ }^{1}$ British University in Egypt (BUE), Cairo, Egypt \\ ${ }^{2}$ Arab East Colleges for Graduate Studies, Riyadh, Kingdom of Saudi Arabia \\ ${ }^{3}$ Princes Sumaya University for Technology, Amman, Jordan
}

\begin{abstract}
A handheld device system, such as cellular phone or a PDA, can be used in acquiring Sign Language (SL). The developed system uses graphic applications. The user uses the graphical system to view and to acquire knowledge about sign grammar and syntax based on the local vernacular particular to the country. This paper explores and exploits the possibility of the development of a mobile system to help the deaf and other people to communicate and learn using handheld devices. The pedagogical assessment of the prototype application that uses a recognitionbased interface e.g., images and videos, gave evidence that the mobile application is memorable and learnable. Additionally, considering primary and recency effects in the interface design will improve memorability and learnability.
\end{abstract}

Index Terms—component; Sign Language; Wireless J2ME; Java Wireless Communication Technologies; JSF; JSP; JMS; SVG; J2SE; Client; Server; Handheld System; Mobile System; TCP/IP; Video Streaming; Adobe After Effects; HTTP Connectivity.

\section{INTRODUCTION}

Cell phones became extremely popular devices considering their vast utility World Wide. However, making cell phones accessible to the deaf is still a challenge. Main available products on the market for this community offer no more than the possibility to boost/amplify volume. Many cellular provides individual cell phone models which are hearing aid compatible and possess speakerphone capabilities. However, if the user is completely deaf, these phones still tend to be somewhat complex or impossible to use [26].

Mobile technology consists of mobile devices and wireless communication technologies. An overview of general wireless communication technologies that can be used in M-learning systems will be introduced next, followed by Table I, which is a comparison between existing wireless technologies.

\section{A. Wireless Communication Technologies}

1) Global System for Mobile Communications (GSM)

GSM is a worldwide mobile telephony system. GSM offers the best voice quality of any current digital wireless standard. GSM provides voice mail, high-speed data, fax, paging and

short message services capabilities, as well as secure communication [10][39].

\section{2) General Packet Radio Service (GPRS)}

GPRS is used for various data applications on phones, including Wireless Application Protocol (WAP), Multimedia Messaging Service (MMS), and software that connect to the Internet. It could be said that, any network connection that is not voice or text messaging uses a data connection like GPRS. GPRS provides about four times greater speed than GSM systems [10].

\section{3) Third Generation (3G)}

$3 \mathrm{G}$ is mobile phone standards and technologies targeting to multimedia communication through cell phone or smart phones. It supports increased bandwidth and high data transfer rates compared to 2 or $2.5 \mathrm{G}$ to allow internet browsing and exchange of audio and video files. In $3 \mathrm{G}$, mobile phones became mobile devices combining a camera, video camera, stereo, MP3 player and radio into one device [18][17].

4) Wireless Fidelity (Wi-Fi)

$\mathrm{Wi}-\mathrm{Fi}$ is a wireless local area network (WLAN). Wi-Fi is technology based on the Institute of Electrical and Electronics Engineers' (IEEE) 802.11 family of standards. Wi-Fi is a wireless network uses radio waves that communicate in two ways. A centralized network with access point, called infrastructure network and decentralized network without access point, called ad-hoc network. Wi$\mathrm{Fi}$ is used for a variety of applications. One of the most common application is home and business WLAN where it can cover around $100 \mathrm{~m}$ with data transfer rate between $10-54$ Mbps [43][42].

5) Worldwide Interoperability for Microwave Access (WiMax)

WiMax provides high speed internet connection for a large number of users over a large area. WiMax can cover range around 31 miles and its data transfer rate between $10-54 \mathrm{Mbps}$. If there are too many users connected to WiMax at the same time, the range will be limited and speed lowered [36] [19].

\section{6) Short Message Service (SMS)}

SMS is the simplest of all the technologies available in the mobile environment. SMS allows single short messages of up to 160 characters to be passed between mobile phones, fax machines or email addresses. Messages are sent along a mobile phone network, and must pass through an SMS centre which handles and manages the messages. SMS is used in an M-learning scenario for dealing with variety of activities such as asking questions, 
providing answers, information delivery and providing feedback [37].

\section{7) Multimedia Message Service (MMS)}

MMS is a more advance technology than SMS which enables the sending and receiving multimedia messages that include multimedia objects (images, audio, video, rich text) between mobile phones. MMS content is longer than SMS and transport on WAP, GPRS or 3G. MMS can also be sent from a mobile phone to an email address [44].

\section{B. Mobile Devices}

The M-learning is impossible without the use of the mobile devices. They vary significantly in their abilities, sizes and prices. The common ability which united them is their mobility and possibility to make wireless connections. Mobile devices can be defined as any electronic devices that are small enough to fit in a shirt or jacket pocket. It would not include laptops, as while they are portable, they are not mobile. Mobile devices should fit in your pocket.

\section{1) Cell Phone}

A cell phone is an electronic telecommunication mobile device. Cell phones commonly named as mobile phones or cellular phones. A cell phone supports voice communication and SMS. The cellular phones from the higher class can access internet via WAP or GPRS technologies. They also can be used to send and receive MMS. A cell phone prices are decreasing continuously [1].

\section{2) $P D A$}

A Personal Digital Assistant (PDA) is pocket-sized computers that fits in hand and has a touch screen or a small keyboard. PDAs support voice communication, fax capability and email service via a wireless network connection. PDAs support software applications such as internet explorer (IE) and calendar. PDAs have evolved and incorporate cell phone and $3 \mathrm{G}$ functions. New PDAs can connect to internet with faster speed via $3 \mathrm{G}$ and $\mathrm{WiFi}$ or WiMax. Most PDAs have Bluetooth and the main operating systems used are Palm OS and Microsoft Pocket PC OS [6] [8].

\section{3) Smart Phone}

A smart phone is a mobile device which combines cell phone and PDA functions. They have smaller sizes than PDA and bigger than cellular phones. Smart phones include backlit color screen, Wi-Fi, Bluetooth, large RAM, large ROM and internet browsers. Smart phone use advanced operating systems (e.g. Symbian, Windows Mobile, etc) which can support advanced applications. It is also possible to insert memory card. Smart phones have potential to be successfully used in the M-learning field [4][32].

\section{4) Tablet $P C$}

Tablet PC are one of the newest mobile devices. They also have full range of capabilities as personal computers. Some of them haven't keyboard but have software to recognize handwritten text and voice-recognition features that will continue to evolve and improve. Because of their large screens and high resolutions, Tablets PCs are good candidates for delivering online courses. They also offer rich data capture and image manipulation features, which can be useful for learning applications [38].
TABLE I.

A COMPARISON BETWEEN EXISTING WiRELESS TECHNOLOGIES [12].

\begin{tabular}{|c|l|l|l|l|}
\hline & $\begin{array}{c}\text { Transfer } \\
\text { Rate } \\
(\mathbf{M b} / \mathbf{s})\end{array}$ & $\begin{array}{c}\text { Range } \\
(\sim \text { meters })\end{array}$ & $\begin{array}{c}\text { Frequency } \\
\text { Band } \\
\text { (GHz) }\end{array}$ & $\begin{array}{c}\text { Number } \\
\text { of users }\end{array}$ \\
\hline Bluetooth & $1-2$ & $10-100$ & 2.4 & Dozens \\
\hline WiFi & $10-54$ & 100 & 2.4 & Dozens \\
\hline GPRS & 0.17 & 30000 & 1.8 & Thousands \\
\hline 3G & $256 \mathrm{kbps}$ & $>1609344$ & Varies & Thousands \\
\hline WiMax & $10-54$ & 49889 & $2-11$ & Thousands \\
\hline
\end{tabular}

Sign languages, like oral languages, organize elementary, meaningless units (phonemes; once called cheremes in the case of sign languages) into meaningful semantic units. The elements of a sign are Handshape (or Handform), Orientation (or Palm Orientation), Location (or Place of Articulation), Movement, and Non-manual markers (or Facial Expression), summarized in the acronym HOLME. Common linguistic features of deaf sign languages are extensive use of classifiers, a high degree of inflection, and a topic-comment syntax. Many unique linguistic features emerge from sign languages' ability to produce meaning in different parts of the visual field simultaneously. For example, the recipient of a signed message can read meanings carried by the hands, the facial expression and the body posture in the same moment. This is in contrast to oral languages, where the sounds that comprise words are mostly sequential (tone being an exception) [35].

In a preliminary experimental result, it has been shown the effectiveness of the novel 3D agent sign language learning system. A 3D agent sign language learning system on mobile devices has been developed which provides an adaptive navigation support and multiple angles of 3D animation view for learners [45]. In [21], authors introduce a Chinese sign language animation system running on mobile devices, which includes three models: 3D virtual human model, word segment based on Chinese sign, and rendering. New wireless technology, educational environments, institution networks and future working and learning methods are studied actively in form of several interesting research projects [12].

The contribution in this paper is to explore the development of a mobile (client-server) system in order to help the deaf and other people to communicate and learn using handheld devices. Although the proposed system was developed to serve Arabic Sign Language users, the system could be adapted to be used with grammar and syntax of other vernacular sign languages. This system also could be developed to administers the network interface/programming, and conducts assessment measurements wirelessly [23]. The front-end (client side) was designed and implemented using a cellular phone or a Personal Digital Assistant (PDA) that have an adequate computational power. The back-end (server side) of the system was designed to run on a server or on the internet. The system is aimed at eventually providing an environment where the deaf can use to manipulate a database/dictionary that contains all the 'words' that are needed to be used regardless of the type of the mobile device. Java wireless communication technologies were suggested in the design. It implements a multi-tier archi- 
tecture in order to integrate different fields of technology. The data generation and acquisition controlled by JSE.

The ultimate objective of the paper is to improve the scalability of the system and to allow for the use of Scalable Vector Graphics (SVG) which makes it possible to create and develop interactive graphical content, with the ability to zoom and resize on displays with different resolutions and aspect ratios.

\section{BACKGROUND}

In Egypt, "a disabled person" means a person who need rehabilitation service to meet the basic needs in society because impairment such as movement-related function, sensory function and mental function brings physical, social, economical and psychological disability[11][9].

Like many other services, special education faces many challenges and limitations. Much effort is being made to meet these challenges; however, these efforts are considered insufficient and must be reconsidered in any future plans. These challenges and limitations are:

\section{A. Financial Limitations:}

Shortages in funding represent a vital challenge for the current delivery of services. Many services need to be revised, expanded, and improved to meet the needs of students with disabilities. Furthermore, new innovations in the field of assistive technology, technical aids, and communication services, demand an increase in financial input which might be difficult [24][11][5][40].

\section{B. Practices and Instructional Limitations:}

Many of the present practices used in providing special education services have quantitative, but not qualitative values. These practical limitations can be described as follow [24]:

- Most institutions and centers for students with disabilities have limited resources to provide effective and suitable services. These institutions have problems not only in the basic fundamental structural components such as inadequate building construction, transportation, class space, staff, health insurance and salaries, but also in their professional practice issues such as teaching methods, disregard of the role of parents, ignoring the importance of in service training, conducting research, providing assistive aids, and improving quality of services .

- Many of the teaching methods used have to be updated in order to improve the quality and quantity of services provided and to follow-up with any new supplementary instruction that increases the efficiency of services provided for a student with disabilities. Applications such as using new editions of diagnostic tools, applying sufficient behavioral management strategies, preparing Individualized Education Plans (IEP) with a good understanding of their roles, using variety of instructional methods, and improving teacher's evaluating strategies, must be included in any future improvement plans.

- The quality of services delivered for a student with disabilities, especially new services including vocational rehabilitation, prevention services, early medical, social, technological support services, and family services, must be encouraged throughout all public, non-profit and private service organizations.
- The government of Egypt places a high priority on disability, with governmental and non-governmental organizations working together to solve disability issues. However, current services cover only about $10 \%$ of the total number of persons with disabilities. The Ministry of Education provides special education services for children with disabilities. It introduced education services for the visually, hearing and mentally impaired through 165 specialized schools and 204 schools, with at least one or more special classrooms for children with disabilities [11].

\section{Information Limitations:}

This problem appears in the absence of accurate and adequate data on the prevalence rate of disability. The effectiveness and efficiency of services need to be evaluated (e.g., placement and identification procedures, early intervention services, assessment and diagnosis practices, and related services applications) and to be used in the future as guidelines for future planning policies and improvements.

According to the Egyptian Central Authority for Public Mobilization and Statistics, there are approximately two million persons with disabilities in Egypt, which represents about $3.5 \%$ of the total population [11], Table II, Table III and Figure 1. Unfortunately, no comprehensive data on disabilities is currently available.

\section{Public Awareness Limitations:}

There is a noted lack of public awareness and insufficient involvement of local communities in supporting, introducing, and conducting services for student with disabilities. Families' needs must be canvassed and addressed by all levels of service providers.

In Egypt, most youth engaging in socially productive work act through religious institutions. A large $67 \%$ of youth look for volunteering opportunities in religious institutions against only $23 \%$ in nongovernment organizations. For example, $47.7 \%$ of those working with the deaf are in religious institutions in comparison to only about $19 \%$ in civil society organizations (CSOs); 38\% help in teaching educational and computer skills in comparison to $17.7 \%$ in $\operatorname{CSOs}[40]$.

TABLE II.

PERCENT Distribution OF DisABLED PERSONS By TyPe OF DisABILITY IN 1996 AT EGYPT[5]

\begin{tabular}{|l|c|c|c|}
\hline Type & $\mathbf{M}$ & $\mathbf{F}$ & $\mathbf{T}$ \\
\hline 1-Blind & 10.7 & 11.1 & 10.8 \\
\hline 2-Lose of one eye & 1.8 & 1.3 & 1.6 \\
\hline 3-Deaf-dumb & 3.1 & 3.5 & 3.2 \\
\hline 4-Deaf & 1.6 & 1.9 & 1.7 \\
\hline 5-Dumb & 3.9 & 4.6 & 4.2 \\
\hline 6-Lose of one or both arms & 2.1 & 0.6 & 1.6 \\
\hline 7-Lose of one or both legs & 4.1 & 1.4 & 3.2 \\
\hline 8- Mental Retardation & 17.5 & 15.3 & 16.7 \\
\hline 9-Poliomyelitis & 12.8 & 12.1 & 12.5 \\
\hline 10-Paralysis total or partial & 19.4 & 17.6 & 18.7 \\
\hline 11-Other disabilities & 23.1 & 30.6 & 25.8 \\
\hline Total & $\mathbf{1 0 0}$ & $\mathbf{1 0 0}$ & $\mathbf{1 0 0}$ \\
\hline
\end{tabular}


TABLE III.

NUMBER OF PERSONS WITH DISABILITIES BY TYPES OF DISABILITY IN 1996 AT EGYPT[11]

\begin{tabular}{|c|c|c|c|c|}
\hline $\begin{array}{c}\text { Total } \\
\text { Number of } \\
\text { Persons } \\
\text { with } \\
\text { Disabilities }\end{array}$ & $\begin{array}{c}\text { Visual } \\
\text { Impairment }\end{array}$ & $\begin{array}{c}\text { Hearing } \\
\text { Impairment }\end{array}$ & $\begin{array}{c}\text { Mental } \\
\text { Disability }\end{array}$ & $\begin{array}{c}\text { Mobility } \\
\text { Impairment }\end{array}$ \\
\hline $1,060,536$ & 151,510 & 90,906 & $1,515,100$ & 303,020 \\
\hline
\end{tabular}

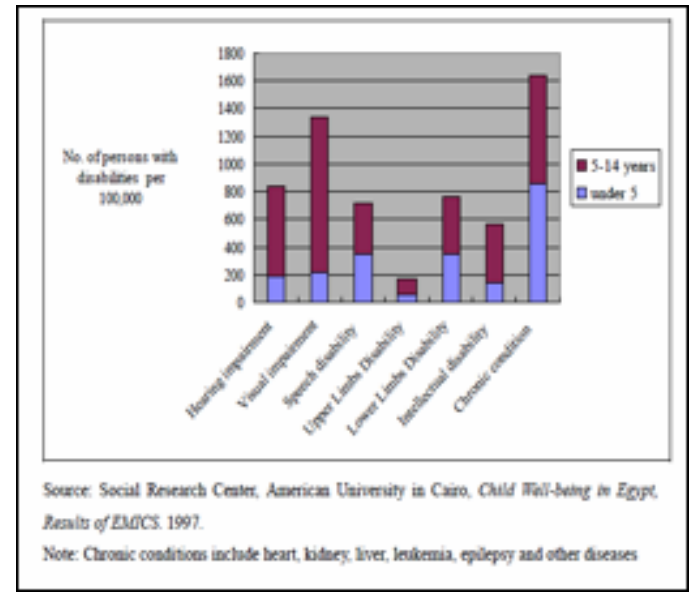

Figure 1. Number of Children with Disabilities per 100,000 by age in 1997 at Egypt [11]

\section{E. Cooperation Limitations:}

There is a lack of cooperation between service delivery systems. The absence of a higher authority to organize, unify, and integrate all efforts to provide comprehensive services, and to accelerate the creation of an effective system of accountability. That is very noticeable in Egypt $[11][5][9][40]$.

\section{The Mobile Tutorial System}

In this paper a digital deaf tutorial system to facilitate learning SL is proposed. The Deaf Tutorial System is defined as a computer-controlled external over a communication medium. It may be considered as a media demonstration, or process, running locally on a software platform but with the ability to be monitored and controlled over the Internet from within a web browser with the host computer connected to the Internet. The client can be any computer connected to the Internet running a browser or mobile device. Once connected, the client will see the same front panel (i.e. interface) as the local host and also have the same program functionality [13].

This system is designed to enable users to control a system via a handheld device, such as a cellular phone or a PDA, and to monitor its output anytime and anywhere, as shown in Figure 2. The hardware infrastructure includes a server and a client end. On the server side, the equipment may include any equipment that can be connected and controlled by a computer [41]. In addition, there is usually a camera on the server end which could be used to output videos activities.

Some of the functions done at the server end include: assessing user-added new words for acceptance or rejection, editing of graphics if needed before acceptance, and review of user reports or questions. Client end functions

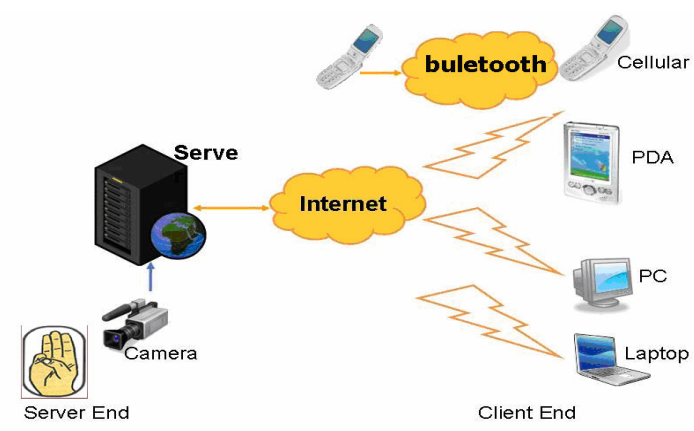

Figure 2. Mobile Deaf Tutorial System Architecture

include: viewing the word/phoneme lists, numbers, nouns/verb representations, pictures and videos, as well as playing games related to the SL for practice [2]. The two end users of the system (client end and server end) are integrated with each other to fulfill the function proposed. The system may be based on a set of tools that teachers in deaf school can combine together and personalize to suit appropriate [33], see Figure 2.

Java language was suggested for the development of the front-end model because it is well suited for interactive web applications and offers the feature of multithreading to enable many people to work on the same area setup simultaneously. It is a very innovative language which allows one to write programs that can be embedded in Internet web pages. Java is a good candidate since the entire system of building remote tutorials relies on the Internet. The deaf child's parent in this environment could log-on from any system. As Java is a machine independent language, which creates programs that run on a wide variety of computers using a range of operating systems, the Java program does not execute directly on the computer and hence it will not interfere with the operating systems or user's data. Instead, as it runs on a standard hypothetical computer called 'Java virtual machine'. This solves the problems of security and unauthorized access. In addition, Java is an Object Oriented programming language unlike others like Common Gateway Interface (CGI) and HTML. Therefore, Java programs can be easily maintained, as reusability of code is possible [15].

The portability of a Java virtual machine is specifically designed from the start for small, resource-constrained devices. The high-level design goal for it was to create the smallest possible "complete" Java virtual machine that would maintain all the central aspects of the Java programming language, but would run in a resourceconstrained device with only a few hundred kilobytes total memory budget [7].

The client design process could be based on J2ME (Java Micro Edition) through TCP/IP protocol to connect to the server. The PDA wireless functions were then utilized to connect to the Internet through which the information was transmitted to log-in to the server to monitor the system. This system not only has the PDA application monitor and control, but also has characteristic display, remote images display, and instruction materials. This system includes the server-end control media and client-end teaching media based on the PDA [15].

In order to find the most appropriate solution for the aforementioned problems, the paper proposes that the project could evolve through the following four phases: 
A. The Analysis phase:

We analyzed the required information that had been gathered with the help of the deaf educators. This phase helped to discover what the project should include, what makes it useful, and how it can be created. After the analysis phase, building the database/dictionary was started.

\section{B. The Design phase:}

In this phase, the screen picture and the video tutorial had been designed. The video tutorial is suitable for both mobile and online sites. The screen picture and the video tutorial are the working base during the implementation phase.

In designing the Mobile Tutorial System (MTS), the View Control Data architecture has been employed to separate the authoring module from the learning module. The system architecture is based on the wireless J2ME communication technology for the client tier, J2SE for the server tier, and the Microsoft SQL server for the data tier. This SL dictionary/database includes a large number of word-concepts, images, and videos in SL. The site could allow the instructor to add undefined words, representations, and videos with certain conditions, (see the dataflow diagram in Figure 3).

HTTP connectivity and a data stream are used to implement the remote connectivity between client and server tier. The MTS has two use cases, the authoring case and learning case. In the authoring use case, the admin authority level uses an authoring tool on a PC to edit and to generate the required interactivity and consequently store the final media in the database.

In the end user learning use case, the user launches the mobile system client application on the target mobile device. A typical scenario of a mobile tutorial system media involves the following steps:

- Registration: a user inputs the URL to access the media. The system asks the user to first register for the web before trying to perform the tutorial. Once the user registers, a user login and password should be given for future use. It should be noted that selfregistration is not allowed for any user.

- Logging-in: once the user has obtained a valid login and password, he/she can login to the server.

- Accessing the Media: when a user starts run, system host computer authenticates, and contacts the user's computer, and interacts with user.

- Admin Login: the instructor/teacher login is recognized, new picture and video can be added.

The flowchart of Figure 4 and the system screens in Figure 5 illustrate some of the necessary steps described above. In Figure 4, where (1) appears, it shows the list of options that are valid for this user. The tutorial system client tier application will send user credentials to the authentication servlet in the server tier. A servlet will authenticate user credential against the user profiles database and generate an XML file. The user will be asked for ID and Password as displayed on screen. The mobile client application will parse the XML file, and if it is a valid login, it will display a list of options dedicated for the specific user.

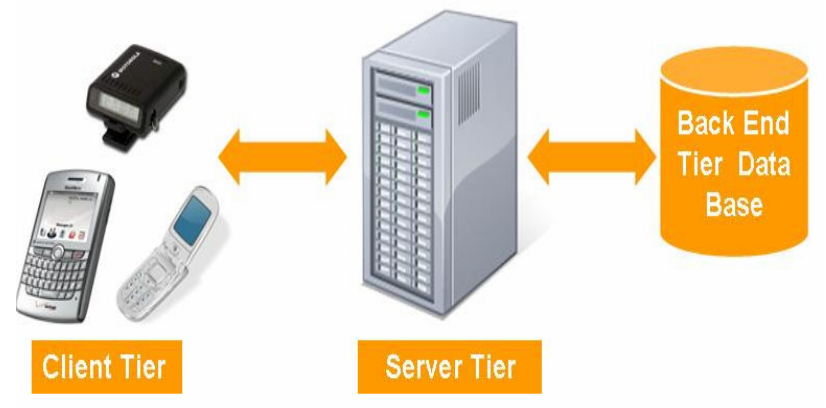

Figure 3. The Mobile Dataflow Diagram

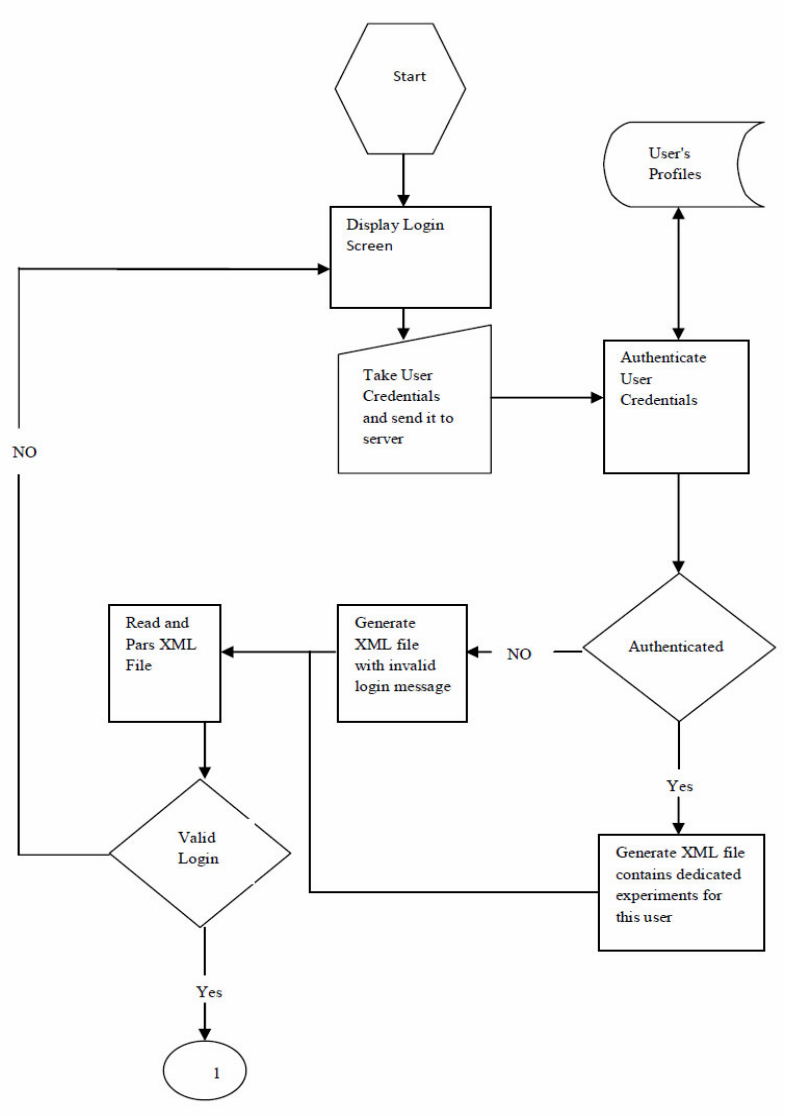

Figure 4. System Software Flowchart

The mobile system client will then extract the user selection and send it to the selection generation servlet in the server tier. The mobile client will eventually parse the XML file and generate the media interface for various types of mobile devices. The latter two figures in Figure 5 depict a video which the user views.

\section{The Implementation phase}

Based on the design phase, the screens could be implemented using Java Server Faces (JSF) or Java Server Page (JSP), and the middleware Java Message Service (JMS). For mobile telephone application J2ME could be used. In addition, Photoshop could be used to edit the pictures, and Adobe After Effects to convert the videos to gif animation [25].

Users on the client side can access and control the equipment using a PC, a laptop, a cellular phone, or PDA, or any similar device. The design could be based on 
transmit standards, including RS232, IrDA, and Wireless Local Area Network (WLAN); thus, students can use mobile devices from remote sites [22].

The client design process could be based on J2ME via TCP/IP protocol to connect to the server. The PDA wireless functions were then utilized to connect to the Internet through which the information was transmitted to log-in to the server. This system not only has the PDA application monitor and control, but also has characteristic display, images display, and instruction materials. This system includes the server-end control media and clientend teaching media, based on PDA remote monitoring and control, and on-line learning materials [22].

J2ME was suggested as the platform to implement the MTS because of its great connectivity and portability. What J2ME can do for mobile devices is just the same as what Java 2 Standard Edition (J2SE) and Java 2 Enterprise Edition (J2EE) did for desktop and server systems. In J2ME, the Connected Limited Device Configuration (CLDC) defines a generic "configuration" for a broad range of handheld devices through implementing a set of CLDC [46].

The main benefits, where CLDC devices are involved, include cross platform - where work is transferred between CLDC and other devices; dynamic content - where content is determined by user experience; and information transfer between CLDC and other devices, security, and the developer community - where the developer talent needed for these devices already exists and is readily available for CLDC devices [16]. A Java virtual machine implementation and a configuration specification CLDC are very closely aligned.

Together they are designed to capture just the essential capabilities of each category of device. On top of the CLDC, the Mobile Information Device Profile (MIDP) is defined specifically for wireless devices such as cell phones and PDAs. Wireless device manufacturers need to implement MIDP in order to support Java applications on their devices. A J2ME profile MIDP is layered on top of (and thus extends) a configuration CLDC. The main goal of a profile is to guarantee interoperability within a certain vertical device family or domain by defining a standard Java platform for that market. Profiles typically include classes are far more domain-specific than the class provided in a configuration CLDC. One main advantage of the mobile system is scalability. It may be improved further using the 2D Scalable Vector Graphics (SVG) API specification. SVG is a new vector-based, open-standard file format developed by the World Wide Web Consortium, which represents a new generation of dynamic, data driven, and interactive graphics [14].This SVG defines anAPI for rendering 2D graphics in the World Wide Web Consortium (W3C) SVG Tiny format [30]. The SVG also makes it possible for developers to create interactive graphical content, with the ability to zoom and resize on displays with different resolutions and aspect ratios. Furthermore, J2ME also defines a subset of the Micro Document Object Model ( $\mu \mathrm{DOM})$ API to allow user interaction and dynamic manipulation of SVG content. Developers can take advantage of the large amount of available SVG content. Because SVG is based on XML, a developer accustomed to this scripting environment can also take advantage of the robust features offered by a full programmatic environment, such as the Java language.
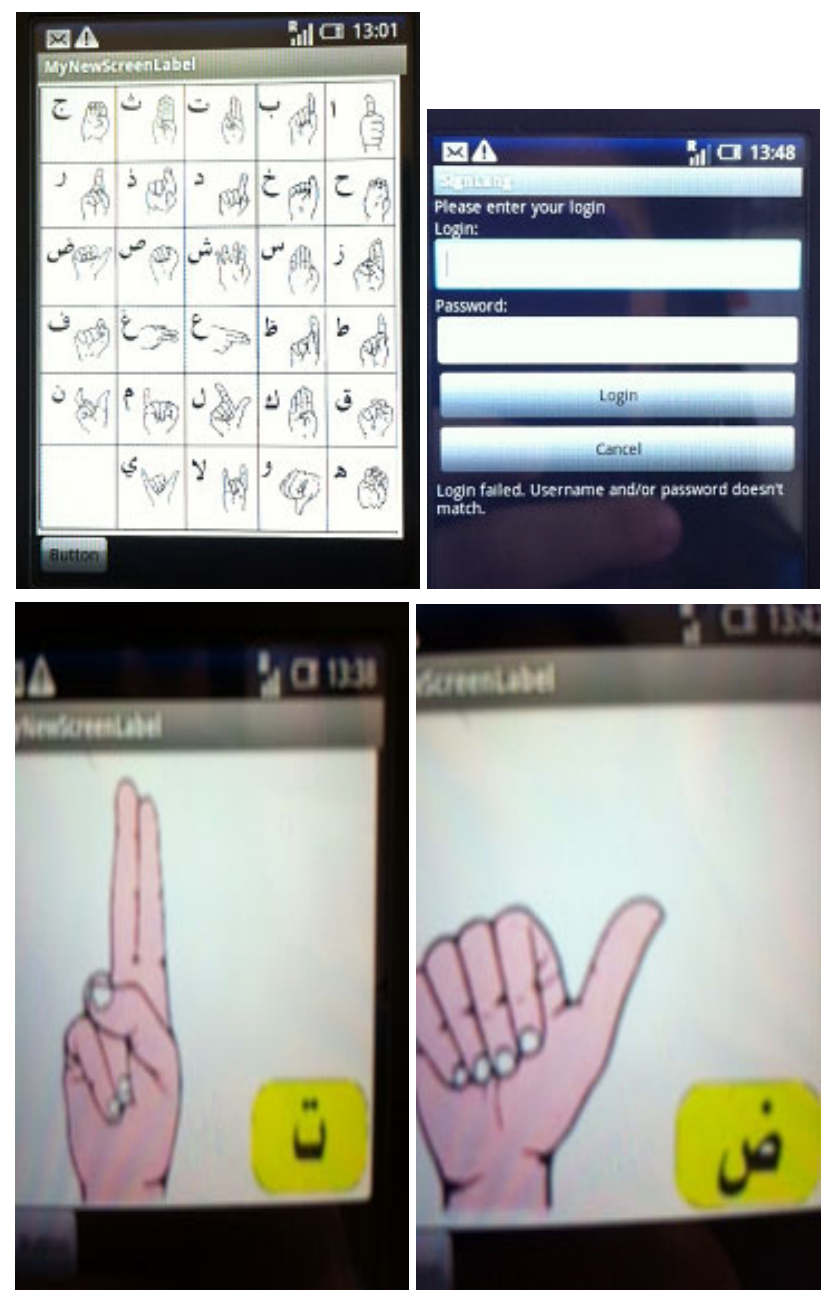

Figure 5. Some system screens

As a result, a user friendly client-side interface that allows the media configuration and parameters to be controlled interactively by the user could be developed. This interface could be realized by means of the SVG file format. An interactive web page can be created with SVG and J2ME, where the client may configure the measurement to be performed. Several setups may be prepared for direct selection, and the corresponding letter table pops up by clicking on the various elements in the sign language diagram.

\section{Testing}

After implementing the screens, testing was performed in order to discover errors without delaying the project process. The following section illustrates the results of some sample testing. The sample testing trying to answer the question of, would this application teach participants Arabic sign language?

\section{E. Pedagogical Evaluation}

In the area of Mobile learning, studies conducted to measure learnability, the evaluation was performed through repeating the task at least twice because the learnability of mobile phones can only be measured if tasks are performed twice[28]. Ziefle ([28] tested learnability in a study with 30 novice and 30 expert users who solved six tasks. In Bay's study [34], users were asked to 
solve four different tasks twice on a simulated Nokia 3210 mobile phone.

Learnability refers more to the beginning of the learning process whereas learnability is very often defined as being the time required learning to perform a specific set of tasks [3]. In our context, we defined learnability as the degree to which users feel they are able to start identifying and recalling the Arabic sign letters. The repetition is the re-learning, which is the situation where learning material a second time will typically and it will take less time and effort than initial learning. This process is represented by the learning curve. "A learning curve is a graphical representation of the changing rate of learning (in the average person) for a given activity or tool. Typically, the increase in retention of information is sharpest after the initial attempts, and then gradually evens out, meaning that less and less new information is retained after each repetition. The learning curve can also represent at a glance the initial difficulty of learning something and, to an extent, how much there is to learn after initial familiarity" [3].

Nielsen, Bevan, Macleod and Thagard [20][31][29] mention that memorability increases re-learnability to a great extent, but it does not replace it. Nielsen [20] states that recognition is better than recall. People tend to remember images better than text. The prototype application considers these issues and uses an image and video. The other issues that affect memorability are the primary and recency effect. People tend to remember facts or information at the beginning and the end of an experience or list. For example, in a list of 20 words, people usually remember the first and last two words from the list [27].

In that respect, it is important to test the learnability and memorability of the pedagogical application of the Arabic sign letter. The studies using mobile application prototype are answering the following two questions:

1. After how many trials will participants be able to learn all alphabetic?

2. Would the letter's location in the list affect memorability?

The mobile application prototype interface has an image that has of all Arabic letters and its mapping hand's signs and a video repeating the letter twice and showing the hand sign of each letter (see Figure 5). The prototype interface of the application had been installed on Sony Ericsson Xperia. At the beginning of the study, participants were informed with the procedures of the study. Participants see the image, watch the video, and answer five multiple-choice question's trial (see Figure 6). At the end of the study, comments about the application were collected.

In order to answer the $1^{\text {st }}$ question, two studies have been conducted. The first study considered repeating the process of watching the image and the video and answering the questions five times. Based on the results of the first study, the decision was taken to make a second study that repeats the producers however seven times.

In order to answer the $2^{\text {nd }}$ question, the design of the five multiple-choice questions per trial for the first study was as follow:

- The second question is randomly chosen from the first three letters presented in the video to assess the primary effect

\section{Trial 1}

1-From the following images, please select the image that represents
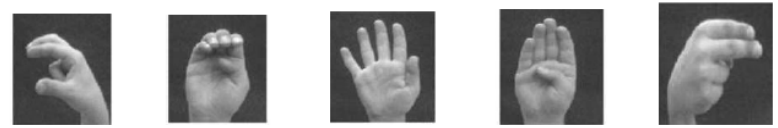

2- From the following images, please select the image that represents
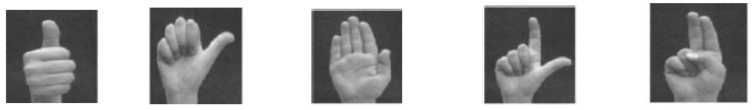

3-From the following images, please select the image that represents $j$
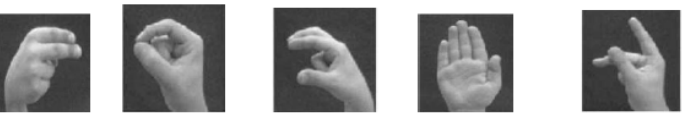

4- From the following images, please select the image that represents
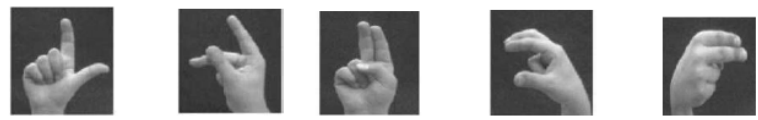

5- From the following images, please select the image that represents
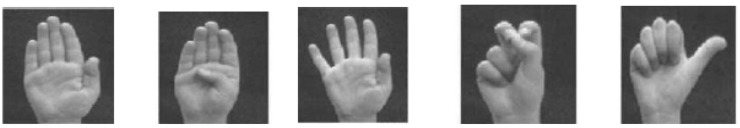

Figure 6. First Multiple-Choice Question Trial

- The fourth question is randomly chosen from the last three letters presented in the video to evaluate the recency effect,

- Questions one, three and five were randomly chosen from the rest of the alphabetic list, (see Figures $5 \&$ $6)$.

Both studies were conducted in a quite office. On average, both studies took around 40-45 minutes to finish. For both studies, 31 participants took part. 20 participants were in the first study and 11 participants in the second one.

In the first study, 52\% were male and $48 \%$ were female. $60 \%$ were from the age range $17-21$ years old, $35 \%$ are from 21-30 years old and 5\% from 31-40 years old. $85 \%$ of the participants are students and $15 \%$ are teaching assistants at the computer science department of the BUE University, see column (a) at Figure 7.

In the second study, 11 people participated. $60 \%$ are females and $40 \%$ are males. $60 \%$ are from $17-20$ years old and 40\%are from 21-30 years old. Majorities are students $90 \%$ and only $10 \%$ are teaching assistant, see column (b) at Figure 7.

The first study gives evidence that the second and fourth questions are memorable. The average correct answers are $96.2 \%$ and $96 \%$ for questions two and four respectively (see Figure 8). The learning curve in Figure 9 did not show that the first trials perform worse that the following ones. However, if the first trial is dismissed, there are some evidences that repeating the procedures improves learnability. Consequently, to check whether repeating the procedures increases the average of correct answers, the second study has been conducted and two trials had been added to become seven trials. The results 


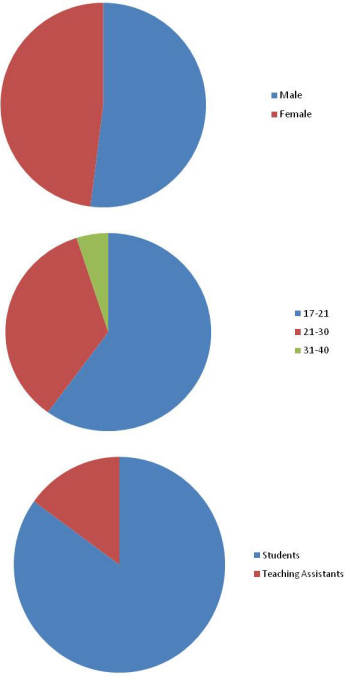

(a)
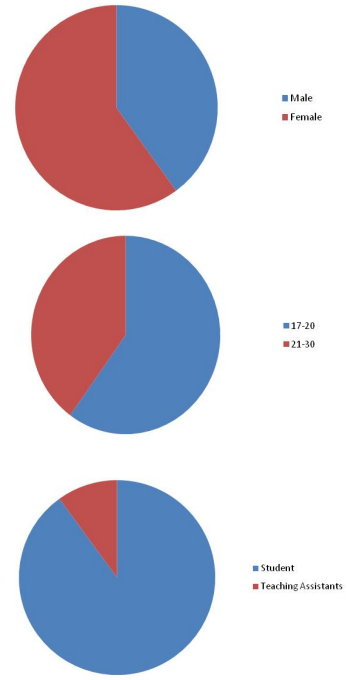

(b)
Figure 7. a) First trial b) Second trial

proofed that repeating the steps of watching the image and the video improves learnability (see Figure 11). Figure 10 supports the argument of primary and recency effect. The second and fourth questions average scores are better that the questions one, three, and five. The average correct answers for questions two and four are $94 \%$ and $82 \%$ respectively.

The results gave evidence of the memorability and learnability of system. Furthermore, it was well received by the participants. There comments were:

- The pace of the video and in particular the repetition of each letter was perceived positively.

- A few number of participants commented on the angle of the hand sign picture (i.e., if the picture captured was a bit right or left to the hand, in some cases, the figures were not very clear). For example, letters such as (dal)-( $(د)$ and (thal)-(ذ) can look the same if the hand sign picture is captured from the right. Hence, for each letter, having different pictures of the hand sign that are captured from different angles can minimize confusion and speed up learning process.

- Very few participants commented on the sound however one participant said that a more friendly sound would improve the application.

\section{CONCLUSIONS}

The MTS system was developed to enable deaf students to access media using cellular phones, PDAs, smart phones, Palms, Pocket PCs, Tablet PCs, and any other similar handheld devices. This allows for teaching to be conducted anytime, anywhere, and allows resources and equipment to be shared between various collaborating institutions. The system allows also for the use of Scalable Vector Graphics (SVG) which makes it possible to create and develop interactive graphical content. Moreover, MTS system could be developed to administer the network interface/programming, and conduct assessment measurements wirelessly [23].

To execute the aforementioned four phases of the MTS systems, we should proceed as follows:

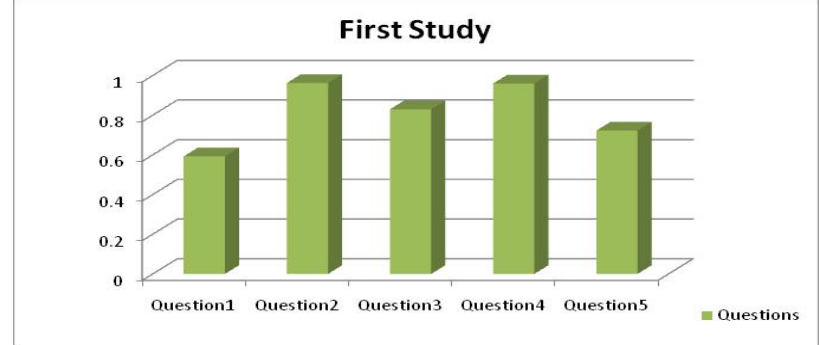

Figure 8 . the avarage correct answer of each question for the first study

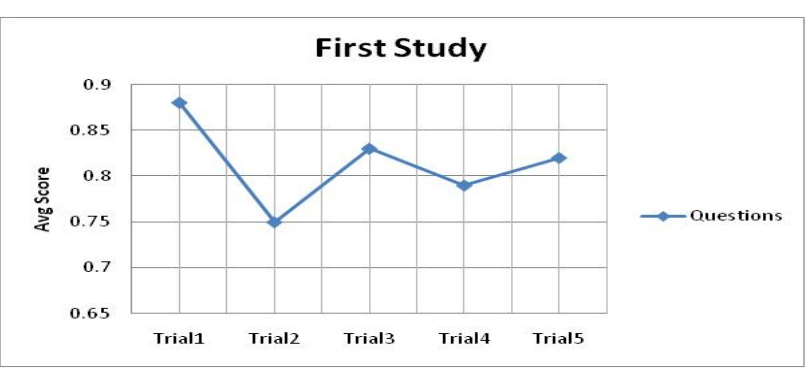

Figure 9. the avarage correct answer of each trial for the first study

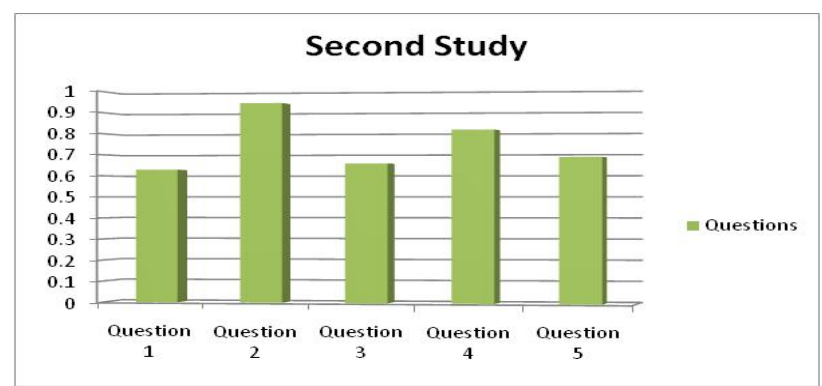

Figure 10. the avarage correct answer of each question for the second study

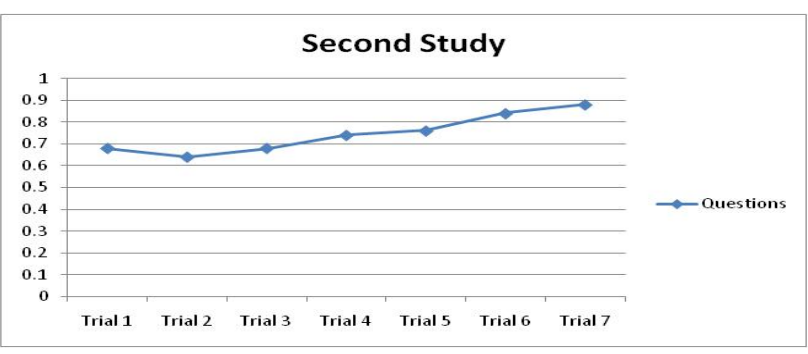

Figure 11. the avarage correct answer of each trial for the second study

\section{A. MTS Implementation}

MTS should be executed such that Adobe After Effects is used to convert the videos to gif animation, that method is used to put an animation of a video online without streaming the video itself. SVG user friendly client-side interface that allows the media configuration and parameters to be controlled interactively by the user will be added.

\section{B. MTS upgrading}

MTS should be upgraded such that the site will allow the instructor to add undefined words, representations, and videos with certain conditions, to the dictionary/database.

The interface of the application that is recognitionbased has a good impact on learnability and memorability. 
To improve the interface, the results of the primary and recency effects could be utilized by allowing users to choose any letter to watch its video or shuffling the letters before starting the application. Furthermore, after watching the image and the video, testing their knowledge by developing an exam similar to memory games could make the experience enjoyable and improve learnability.

The MTS ultimate goal is to develop the MTS system as an interactive graphical teaching tool for any subject, anytime, anywhere and to any person, hearing or deaf.

\section{REFERENCES}

[1] A. A. Economides and N. Nikolaou, "Evaluation of Handheld Devices for Mobile Learning", International Journal of Engineering Education, 24(1), 2008.

[2] A. Alkouz, A. Y. Al-Zoubi, and M. Otair, "J2ME-Based Mobile Virtual Laboratory for Engineering Education", International Journal of Interactive Mobile Technologies (iJIM), Vol 2, No 2, 2008 .

[3] A.G. Bills, General experimental psychology, Longmans Psychology Series, pp. 192-215, New York, NY: Longmans, Green and Co, 1934. http://dx.doi.org/10.1037/11314-010

[4] A. Holzinger, A. Nischelwitzer, and M. Meisenberger, "Mobile Phones as a Challenge for M-Learning: Examples for Mobile Interactive Learning Objects (MILOs)", Third IEEE International Conference on Pervasive Computing and Communications Workshops (PERCOMW'05). p. 307-311, 2005. http://dx.doi.org/ 10.1109/PERCOMW.2005.59

[5] B. El-Deeb, "Disability Statistics in Egypt", Paper Presented at Washington Group meeting in Ottawa, Canada, Jan, 2002.

[6] C. Houser, P. Thornton, and D. Kluge, "Mobile Learning: Cell Phones and PDAs for Education", Proceedings of the International Conference on Computers in Education (ICCE'02), IEEE. p. $1149-1150,2003$.

[7] C. W. Lund, and M. S. Norum, The Peer2Me Framework - A Framework for Mobile Collaboration on Mobile Phones, Master's Thesis, NTNU, 2005. http://www.chwlund.com/archive/thesis 2005.pdf

[8] D. Lindquist, T. Denning, M. Kelly, R. Malani, W.G. Griswold, and B. Simon, "Exploring the Potential of Mobile Phones for Active Learning in the Classroom", ACM SIGCSE Bulletin, 39(1): p. 384-388, 2007. http://dx.doi.org/10.1145/1227504.1227445

[9] Department of Social Rehabilitation, Ministry of Social Affairs, Rehabilitation and Care of the Handicapped in A.R.E. http://digitalcommons.ilr.cornell.edu/gladnetcollect/233/.

[10] E. Egea-Lopez, A. Martinez-Sala, J. Vales-Alonso, J. GarciaHaro, and J. Malgosa-Sanahuja, "Wireless communications deployment in industry: A Review of Issues, Options and Technologies", ScienceDirect, Computers in industry, 56(1): p. 29-53, 2005. http://dx.doi.org/10.1016/j.compind.2004.10.001

[11] Egyptian Planning and Evaluation Department, Country Profile on Disability, Arab Republic of Egypt, Japan International Cooperation Agency,March,2002. http://digitalcommons.ilr.cornell.edu/ gladnetcollect/233/

[12] E. Koskinen, U. Veitonen, T. Lasksonen, and O. Vaananen, "New Generation Wireless Technologies Impact on Educational Environments Case: Utilizing Finnish Sign Language in Interpreter Training", Proceedings of the 2005 IEEE International Workshop on Wireless and Mobile Technologies in Education (WMTE'05), 2005. http://dx.doi.org/10.1109/WMTE.2005.48

[13] F. P. Bergenti, and A. Leap, "A FIPA Platform for Handheld and Mobile Devices", ATAL 2001 Conference, Seattle, USA, 2001.

[14] G. Alonso, F. Casati, H. Kuno, and V. Machiraju, Web Services Concepts, Architectures and Applications, Springer Verlag. page 8, 2004.

[15] J. Alja'm, S. A. El-Seoud, A. E. Block, M. Garcia-Ruiz, and A. M. Jaoua, "An Assistive Computerized Systm for Children with Intellectual and Learning Disabilities", Lecture Notes in Computer Science (LNCS), Springer, June, 2009.

[16] J. B. Freysen, "M-learning: an Educational Perspective", Mobile Learning Anytime Anywhere, A book of papers from MLEARN
2004, Edited by Jill Attewell and Carol Savill-Smith, Published by the Learning and Skillls Development Agency (www.LSDA.org.uk), pp. 73-75, 2004.

[17] J. Keogh, The Complete Reference J2ME, Published by McGrawHill OSBORNE Edition, 2003.

[18] J.L. Gimenez López, T. Magal-Royo, J. García Laborda, and F. Garde Calvo, "Methods of Adapting Digital Content for the Learning Process via Mobile Devices", Procedia - Social and Behavioral Sciences, Volume 1 (Issue 1), pp. 2673-2677, 2009.

[19] J. Malek, M. Laroussi, A. Derycke, and H. Ben Ghezala, "A Context-Aware Approach for Modeling Bijective Adaptations between Context and Activity in a Mobile and Collaborative learning", International Journal of Interactive Mobile Technologies (iJIM), 2(1), 2007.

[20] J. Nielsen, Coordinating user interfaces for consistency. Boston, MA: Academic Press, 1989

[21] J. Wang, Y. aun, and L. Wang, "Chinese Sign Language Animation System On Mobile Devices", Second International Conference on Information Technology and Computer Science, (DOI 10.1109/ITCS.2010.19), 2010. http://dx.doi.org/10.1109/ITCS. $\underline{2010.19}$

[22] K. Smiley, IT Trends : Mobile and Wireless Devices, Giga Information Group, 2003.

[23] M. Abu Shaira, and I. A. Alzraigat, "The Effect of Sign Writing on the Achievement and Acquisition of Vocabulary by Deaf Students", Al-Amal School for Deaf, Amman-Jordan, May 2007.

[24] M. Al jabery, and M. Zumberg, "General and Special Education Systems in Jordan: Present and Future Perspectives", International Journal of Special Education, Vol. 23, No. 1, 2008.

[25] M. Brachtl, J. Slajs, and P. Slavik, "PDA Based Navigation System for a 3D Environment", In Third International Workshop on Intelligent Interactive Assistance and Mobile Multimedia Computing (IMC'2000), Rostock-Warnemu“nde, Germany, 2000.

[26] M. Jemni, O. E. Ghoul, N. B. Yahia, and M. Boulares, "Sign Language MMS To make Cell Phones Accessible To DEAF AND Hard-of-Hearing Community", Conference \& Workshop on Assistive Technologies for People with Vision \& Hearing Impairments, Assistive Technology for All Ages, M.A. Hersh (ed.), CVHI 2007.

[27] M. J. Gelb and K. Howell, Brain Power: Improve Your Mind as You Age, New World Library Publisher, 2012.

[28] M. Ziefle, The influence of user experience and phone complexity on performance, ease of use and learnability of different mobile phones, Behaviour \& Information technology, Vol. 21, No. 5, 303-311, 2002. http://dx.doi.org/10.1080/0144929021000048538

[29] N. Bevan, and M. Macleod, Usability measurement in context, Behaviour \& Information Technology Vol. 13 No. 1 and 2, 132 $145,1994$.

[30] P. Contreras, D. Zervas, and F. Murtagh, Web Services in Natural Language: Towards an Integration of Web Service and Semantic Web Standards in the JXTA Peer to Peer Environment, page 65, May 2005.

http://thames.cs.rhul.ac.uk/ wstalk/papers/rhulpapers/orchestratio n.pdf

[31] P. Thagard, Mind, introduction to cognitive science. Cambridge, MA: The MIT Press, 1996.

[32] P. Zheng, L. M. Ni, "The Rise of the Smart Phone. IEEE Distributed Systems Online", 7(3): p. 1-14, 2006.

[33] R. J. Costa, and G. R. Alves, "Remote and Mobile Experimentation: Pushing the Boundaries of an Ubiquitous Learning Place" 9th IFAC Symposium on Automated Systems Based on Human Skill And Knowledge (ASBoHS'06), França-Nancy, $22^{\text {nd }}$ to $24^{\text {th }}$ of May, 2006.

[34] S. Bay, "Cellular Phone Manuals: Users' Benefit from Spatial Maps", Proceedings of ACM CHI 2003, Ft. Lauderdale, Florida, 662-663, 2003.

[35] Sign Language, http://en.wikipedia.org/wiki/Sign_language .

[36] S. M. Jacob, and B. Issac, "Mobile Technologies and its ImpactAn Analysis in Higher Education Context", International Journal of Interactive Mobile Technologies (iJIM), 2(1), 2008.

[37] S. R. Balasundaram, and B. Ramadoss, "SMS for QuestionAnswering in the m-Learning Scenario", Journal of Computer Science, 3(2): p. 119-121, 2007. http://dx.doi.org/10.3844/ jessp.2007.119.121 
[38] S.S. Mahmoud, "A proposed Model for Distributing e-Courses Content through Mobile Technology Architectures", Proceedings of World Academy of Science: Engineering \& Technology, Vol. 39, p274, February 2008.

[39] T. Georgiev, E. Georgieva, and A. Smrikarov, "M-learning-a New Stage of -Learning", International Conference on Computer Systems and Technologies. 2006.

[40] The Institte of National Planning, The Egypt Human Development Report, the Human Development Project, Egypt, under the project document EGY/01/006 of technical cooperation with the United Nations Development Programme (UNDP), 2010. http://hdr.undp.org/en/reports/nationalreports/arabstates/egypt/Egy pt 2010 en.pdf

[41] T. Menzies, 21st Century AI: Proud, Not Smug, IEEE Intelligent Systems. 18-25, 2003. http://dx.doi.org/10.1109/MIS.2003. $\underline{1200723}$

[42] T. Zahariadis, "Evolution of the Wireless PAN and LAN standards", Computer Standards \& Interfaces, Sciencedirect,. 26(3): p. 175-185, 2004. http://dx.doi.org/10.1016/S0920-5489(03)00093-X

[43] Wireless Fdelity (Wi-Fi): 4G Americas, http://www.4gamericas. org/index.cfm? fuseaction=page\&sectionid $=260$

[44] W. P. Lee, M. A. Osman, M. Sabudin, S. Sulaiman, L. A. Zadeh ,J. Kacprzyk, N. Mastorakis, A. Kuri-Morales, P. Borne, and L. Kazovsky "An Experience on Introducing a Mobile Community Platform: Flying 2 U", in WSEAS International Conference. Proceedings. Mathematics and Computers in Science and Engineering, World Scientific and Engineering Academy and Society, 2010
[45] Y. Lin, J.J. Leu, J. Huang, and Y. Huang, "Developing the Mobile 3D Agent Sign Language Learning System", The 6th IEEE International Conference on Wireless, Mobile, and Ubiquitous Technologies in Education, (DOI 10.1109/WMUTE.2010.25), 2010.

[46] Z. Wang, Z. Guo, and Y. Wang, "J2ME-Based Application of Vector Space in Query Optimization", ISECS International Colloquium on Computing, Communication, Control, and Management CCCM, Volume2, 2008 .

\section{AUTHORS}

M. Samir Abou El-Seoud, Ann Nosseir, and Islam Taj-Eddin are with Faculty of Informatics and Computer Science, British University in Egypt-BUE, Cairo, Egypt. \{samir.elseoud; ann.nosseir; islam.tajeddin\}@bue.edu.eg

Hosam El-Sofany is with Arab East Colleges for Graduate Studies, Dept of Computer Science, Riyadh, Kingdom of Saudi Arabia. hosam_elsofany@hotmail.com

Nadine Abu Rumman is with The King Hussein School for Information Technology, Princess Sumaya University for Technology (PSUT), Jordan. Nadine@psut.edu.jo

This article is an extended and modified version of a paper presented at the International Conference on Interactive Collaborative Learning (ICL2012), held 26 - 28 September 2012, in Villach, Austria. Received 28 November 2012. Published as resubmitted by the authors 20 December 2012 . 